\title{
The POSEIDON stratification - moving from poor ovarian response to low prognosis
}

\author{
Matheus Roque ${ }^{1}$, Thor Haahr ${ }^{2,3}$, Sandro C. Esteves ${ }^{3,4}$, Peter Humaidan ${ }^{2,3}$ \\ 1MATER PRIME - Reproductive Medicine, São Paulo, SP, Brazil \\ ${ }^{2}$ The Fertility Clinic Skive Regional Hospital, 7800 Skive, Denmark \\ ${ }^{3}$ Faculty of Health, Aarhus University, 8000 Aarhus C, Denmark \\ ${ }^{4}$ ANDROFERT, Andrology and Human Reproduction Clinic, Campinas, SP, Brazil
}

\begin{abstract}
Poor ovarian response remains one of the most challenging tasks for an IVF clinician. In this review, we aim to highlight the ongoing research for optimizing the prognosis in poor ovarian response patients. The newly introduced POSEIDON criteria argue that the first step is to move from a poor response to a poor prognosis concept, while improving identification and stratification of the different sub-types of poor prognosis patients prior to ovarian stimulation. The immediate marker of success is the ability of the ovarian stimulation to retrieve the number of oocytes needed to obtain at least one euploid blastocyst for transfer in each patient. This surrogate marker of success should not replace live birth as the most important outcome, but it should be approached as a useful tool for clinicians to evaluate their strategy for achieving live birth in the shortest timespan possible in the individual patient/ couple.
\end{abstract}

Keywords: POSEIDON, poor ovarian response, Bologna criteria, low-prognosis patients, IVF/ICSI, assisted reproduction

\section{INTRODUCTION}

It is estimated that more than 1.5 million in vitro fertilization (IVF)/intracytoplasmic sperm injection (ICSI) cycles are performed every year around the world, and the number of initiated IVF cycles increases by almost $9.5 \%$ per year (Dyer et al., 2016). Ovarian stimulation (OS) the first step in every IVF/ICSI cycle- is crucial to increase IVF outcome, as the development of a sufficient number of follicles and oocytes increase not only the live birth rate per cycle, but, importantly, also the cumulative live birth rate (CLBR) per cycle in ART treatments (Drakopoulos et al., 2016; Siristatidis et al., 2013). Indeed, the number of oocytes retrieved during an IVF treatment is of utmost importance to overcome two critical problems related to female infertility, namely, oocyte competence and ovarian aging.

In regards to oocyte competence, the live birth rate per mature oocyte retrieved is lower than $5 \%$ (Goldman et al., 2013), and the number of oocytes needed to obtain at least one live birth increases exponentially with age (Goldman et al., 2017). This increase in the number of oocytes necessary to obtain a live birth is associated with the biological aging of the ovaries, resulting in a progressive decrease in embryo euploidy rates with increasing age (Esteves et al., 2019a).

Importantly, when evaluating OS outcomes, a significant number of patients - ranging from $9 \%$ to
$24 \%$ - exhibit poor ovarian response (POR) to stimulation with exogenous gonadotropins. As a consequence, low pregnancy and live birth rates are obtained, varying from $3 \%$ to $14 \%$ (Tarlatzis et al., 2003; Ulug et al., 2003; Polyzos et al., 2012; 2013; La Marca et al., 2015; Drakopoulos et al., 2016; Humaidan et al., 2017).

The clinical management of the POR patient is challenging, as there is no single intervention, which seems to clearly improve IVF outcomes for this subgroup of patients (Papathanasiou et al., 2016). Although several strategies have been proposed to optimize the ovarian response and the number of oocytes retrieved, currently there is no consensus regarding the most optimal treatment for the POR patient undergoing IVF (Pandian et al., 2010; Papathanasiou et al., 2016, Olgan \& Humaidan, 2017). Moreover, the diversity in the definition of POR introduce significant limitations in interventional trials, as it is likely that patients with different characteristics are compared (Polyzos \& Devroey, 2011; Papathanasiou et al., 2016).

The Bologna criteria (2011) were published in an attempt to standardize the definition and diagnosis of POR, and to compare results as well as to draw reliable conclusions in a more homogeneous population (Ferraretti et al., 2011). According to these criteria, for a woman to be classified as a POR patient, at least two of the following three criteria must be present, namely, (i) Advanced maternal age ( $\geq 40$ years) or any other POR risk factor; (ii) Previous poor ovarian response $(\leq 3$ oocytes retrieved or previous cycle cancelled), and (iii) Abnormal ovarian reserve tests (antral follicle count [AFC] $<5-7$ follicles or Anti-Mullerian hormone $[\mathrm{AMH}]<0.5-$ $1.1 \mathrm{ng} / \mathrm{ml}$ ). Moreover, two episodes of POR after maximal stimulation were deemed sufficient to classify a patient as POR - even in the absence of the other criteria mentioned (Ferraretti et al., 2011). Although the development of the Bologna criteria focused on establishing homogeneous subgroups of patients considered as POR, heterogeneity was still a major problem within the Bologna criteria group (Humaidan et al., 2017; Bozdog et al., 2017; Esteves et al., 2018). Moreover, the Bologna criteria failed to assess the reproductive potential of young POR patients (Cohen et al., 2015; Alviggi et al., 2018; Boots \& Bernardi., 2018).

Notably, there are significant differences in the reproductive outcomes when evaluating patients within different age categories; thus, emphasizing the importance of taking into account quantity as well as the quality of oocytes (Bozdag et al., 2017). Hu et al. (2014) retrospectively evaluated 592 IVF cycles in patients classified according to the Bologna criteria, comparing the outcomes of different ovarian stimulation protocols. Although, not all subgroups of the Bologna criteria were analyzed, there were different reproductive outcomes when comparing patients below and above 35 years of age. 
In their study, the mean implantation rates ranged from $15.3 \%$ to $29.4 \%$ in patients below 35 years, and from $6.3 \%$ to $24.1 \%$ in patients $\geq 35$ years (Hu et al., 2014). Bozdag et al. (2017) conducted a retrospective evaluation of the IVF outcomes of 821 patients who fulfilled the Bologna criteria, and for whom 1,257 ICSI cycles was performed. In this study, the live birth rates were lower than $10 \%$ overall. However, the authors reported differences in results within the Bologna Criteria subgroups, concluding that the subgroups were non-comparable in terms of reproductive potential (Bozdag et al., 2017).

\section{POSEIDON - and the concept of low prognosis}

To overcome the heterogeneity observed within the different groups classified as POR following the Bologna criteria, the POSEIDON (acronym for Patient-Oriented Strategies Encompassing IndividualizeD Oocyte Number) criteria were developed, moving from a poor ovarian response concept to a low prognosis concept. This new concept was introduced to stratify low prognosis patients undergoing ART based on the combination of quantitative and qualitative parameters, proposing a new and more detailed stratification of low prognosis IVF patients (Alviggi et al., 2016). The novel concept of low prognosis -defined in terms of CLBRs per initiated cycle- focusses on improving the management of patients undergoing ART by identifying a more homogeneous population and by suggesting a tailored approach to patient handling, and, thus, providing better tools to maximize IVF success rates. In this review, we aim at presenting the four groups stratified according to the POSEIDON criteria; evaluate their reproductive prognosis and the suggested clinical handling of each group, in an effort to establish the best strategy to improve the reproductive outcomes of the low prognosis patient undergoing an IVF treatment.

\section{Oocyte quantity and cumulative live birth}

The ovarian response and the number of oocytes retrieved after OS are independent predictors of the likelihood of a live birth during an IVF treatment (Sunkara et al., 2011; Drakopoulos et al., 2016). The CLBR per cycle markedly increases as the number of oocytes retrieved increases (Polyzos et al., 2018). In this line, Drakopoulos et al. (2016) reported that the odds ratio (OR) for CLBR significantly increases with the number of oocytes. When comparing the group of patients who had 0-3 oocytes retrieved, patients with 4-9 oocytes had an OR of 2.4 (95\% confidence interval [CI] 1.3-4.4), 10-15 oocytes an OR of 3.5 (95\% CI 1.9-6.7), and >15 oocytes an OR of 5.6 (95\%
CI 3.1-11.6). The group of patients with 4-9 oocytes, which was previously classified as normal, was renamed as suboptimal responders, as the CLBR per initiated cycle was poorer when compared to patients with 10 or more oocytes (Drakopoulos et al., 2016). Thus, concerning the number of oocytes retrieved, two subgroups of patients presented with poorer clinical outcomes, namely, those with $<4$ oocytes retrieved (poor response) and those with 4-9 oocytes (suboptimal response). However, these groups of patients are likely to have different characteristics, as the ovarian reserve, age, and the ovarian response to the treatment may differ among them, and consequently have an impact on CLBR.

Hence, the 'low prognosis' concept fundamentally relates to CLBR, which is defined by the International Committee for Monitoring Assisted Reproductive Technologies (ICMART) as, 'the number of deliveries with at least one live birth resulting from one initiated or aspirated ART cycle, including all cycles in which fresh and/or frozen embryos are transferred, until one delivery with a live birth occurs or until all embryos are used, whichever occurs first, expressed per 100 cycles (initiated or aspirated)' (Zegers-Hochschild et al., 2017).

\section{POSEIDON stratification}

The novel system relies on female age, ovarian reserve markers, ovarian sensitivity to exogenous gonadotropin, and the number of oocytes retrieved, which will both identify the patients with low prognosis and stratify such patients into one of four groups of women with "expected" or "unexpected" impaired ovarian response to appropriate exogenous gonadotropin stimulation. According to these criteria, four distinct groups of low prognosis patients can be established. Group 1 - patients $<35$ years with adequate ovarian reserve parameters (AFC $>=5$ or $\mathrm{AMH}>=1.2 \mathrm{ng} / \mathrm{mL}$ ), presenting with an unexpected poor (<4 oocytes retrieved - Subgroup 1a) or a suboptimal (4-9 oocytes retrieved - Subgroup 1b) ovarian response after OS; Group 2 - patients $>=35$ years with adequate ovarian reserve parameters $(A F C>5$ or $A M H>=1.2 \mathrm{ng} / \mathrm{mL}$ ), presenting with an unexpected poor ( $<4$ oocytes retrieved - Subgroup 2a) or a suboptimal (4-9 oocytes retrieved Subgroup 2b) ovarian response; Group 3 - patients $<35$ years with poor ovarian reserve parameters (AFC $<5$ or $\mathrm{AMH}<1.2 \mathrm{ng} / \mathrm{mL}) ;$ Group 4 - patients $>=35$ years with poor ovarian reserve parameters (AFC $<5$ or $\mathrm{AMH}<1.2 \mathrm{ng} /$ $\mathrm{mL}$ ) (Alviggi et al., 2016; Humaidan et al., 2016; Esteves et al., 2018) - Figure 1 (left). Owing to low oocyte numbers and less embryos produced, POSEIDON patients

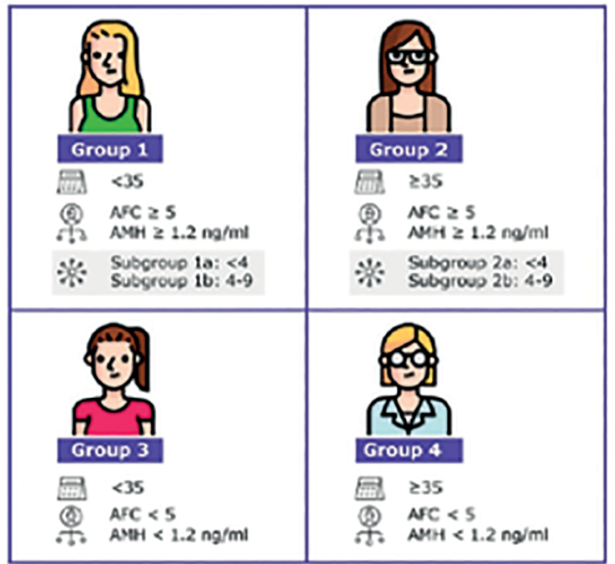

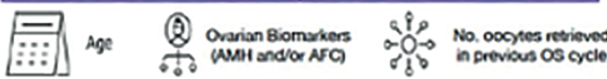

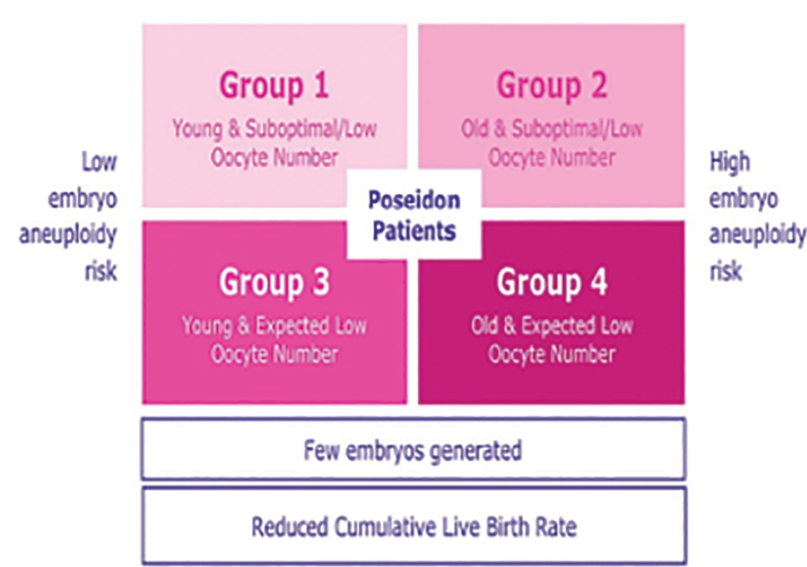

Figure 1. POSEIDON criteria of low prognosis patients in ART. Art drawing by Chloé Xilinas. Modified from Esteves et al. Front. Endocrinol. 2019;10:814. (This is an open-access article distributed under the terms of the Creative Commons Attribution License (CC BY). 
have lower cumulative live birth rates per started cycle than non-POSEIDON counterparts. However, the prognosis is differentially affected by female age as it relates to the risk of embryo aneuploidy - Figure 1 (right).

The POSEIDON stratification is based on the age of the woman, ovarian reserve biomarkers, ovarian sensitivity to exogenous gonadotrophins, and the number of oocytes retrieved during an IVF cycle (if the patient underwent a previous OS), in order to stratify patients with a low reproductive prognosis. Thus, this novel stratification considers both quantitative and qualitative parameters of the patient, and include a new and more detailed stratification system of the infertile patient with "expected" and "unexpected" impaired ovarian response to exogenous gonadotropin stimulation (Alviggi et al., 2016). Importantly, POSEIDON groups 1-4 overall constitute approximately $47 \%$ of patients who undergo an IVF treatment (Conforti et al., 2019a).

In this stratification, POSEIDON groups 1 and 2 patients are those with an adequate ovarian reserve before treatment, but who had a low response to ovarian stimulation in terms of fewer follicles developed and fewer oocytes retrieved than expected from the ovarian reserve biomarkers; thus, leading to a lower CLBR per initiated cycle (Conforti et al., 2019a; Esteves et al., 2019b). The main hypotheses of this suboptimal response or "hyporesponse" to OS are as follows, (i) polymorphisms related to the FSH and $\mathrm{LH}$ receptor, or polymorphisms related to circulating endogenous $\mathrm{LH}$; (ii) suboptimal dosing of gonadotropins; (iii) Asynchronous follicular development during the OS; (iv) technical issues related to ovulation trigger and/or oocyte pickup. In accordance with these hypotheses, future stimulation strategies were suggested (Conforti et al., 2019b) - Figure 2.

The concept of a hypo-response to OS can be estimated by the FORT (follicle output rate) and FOI (follicle-to-oocyte index) (Conforti et al., 2019b). These indices correlate the pool of antral follicles at the beginning of OS to the number of preovulatory follicles at the end of stimulation - FORT (Genro et al., 2011; Gallot et al., 2012), or the number of oocytes retrieved at oocyte pickup - FOI (30). It has been considered that a FORT $<50 \%$ or a FOI $<50 \%$ are suggestive of a hypo-response to stimulation, and subsequently specific strategies should be implemented in the next cycle to overcome the hypo-response (Conforti et al., 2019b) - Figure 3.

POSEIDON groups 3 and 4 patients are patients with a poor ovarian reserve, in whom a poor ovarian response to stimulation is expected during their first IVF cycle (Haahr et al., 2019) - Figure 4. This fact per se gives them a high risk of a poor reproductive outcome, rendering clinical handling more challenging than POSEIDON groups 1 and 2 (Conforti et al., 2019b). With the current worldwide delay in childbearing, POSEIDON group 4 is increasingly being observed during IVF, constituting more than $50 \%$ of the total POSEIDON population in some centers, whereas group-3 patients constitute approximately $10 \%$, only (Haahr et al., 2018a; 2018b; Haahr et al., 2019).

\section{Prognosis among different POSEIDON groups}

When comparing the reproductive outcomes among different POSEIDON groups, a significantly different prognosis is seen in terms of CLBRs, and different treatment strategies should be implemented to change the fate of these patients. Recently, Leijdekkers et al. (2019) used the data from a multicenter observational study (OPTIMIST study) (Van Tilborg et al., 2017a; 2017b; Oudshoorn et al., 2017) to compare the prognosis of patients stratified

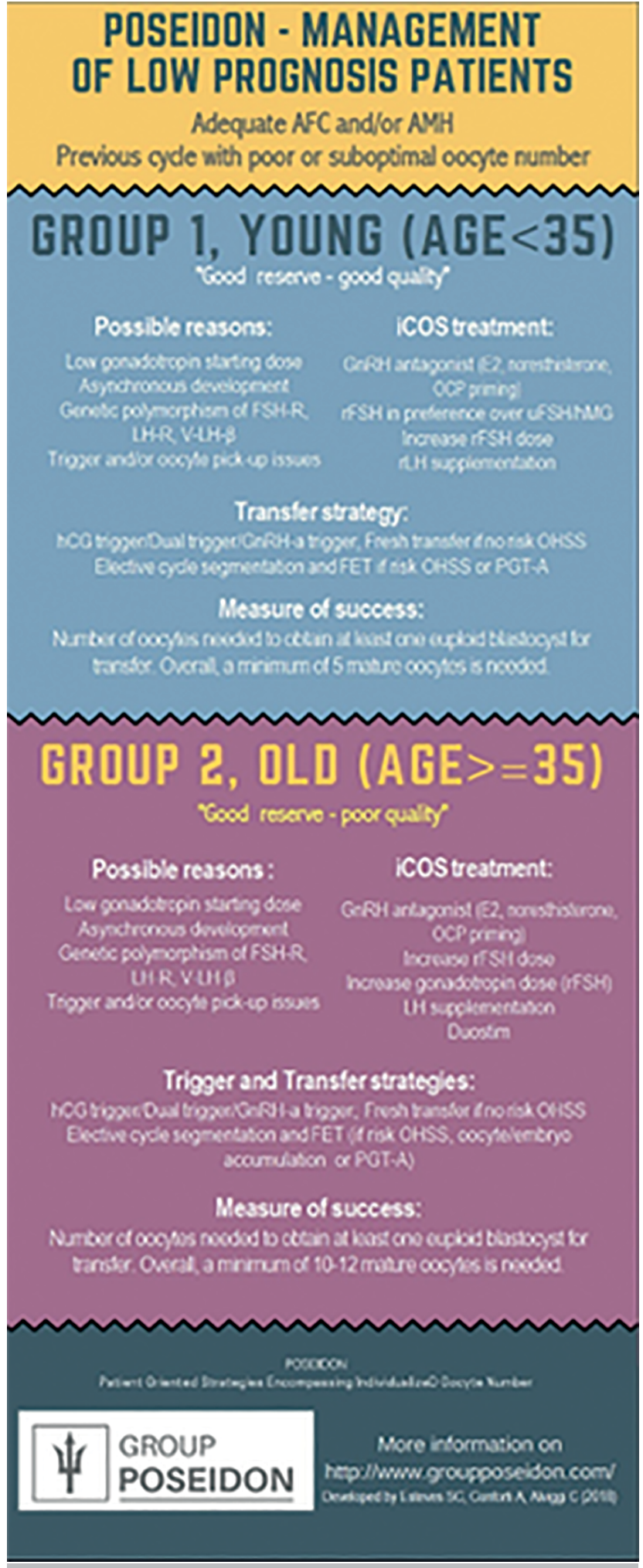

Figure 2. Management overview of low prognosis patients according to POSEIDON groups 1 and 2. Reprint from: Conforti et al. Management of Women With an Unexpected Low Ovarian Response to Gonadotropin. Front Endocrinol. 2019;10:387. This is an open-access article distributed under the terms of the Creative Commons Attribution License (CC BY). 


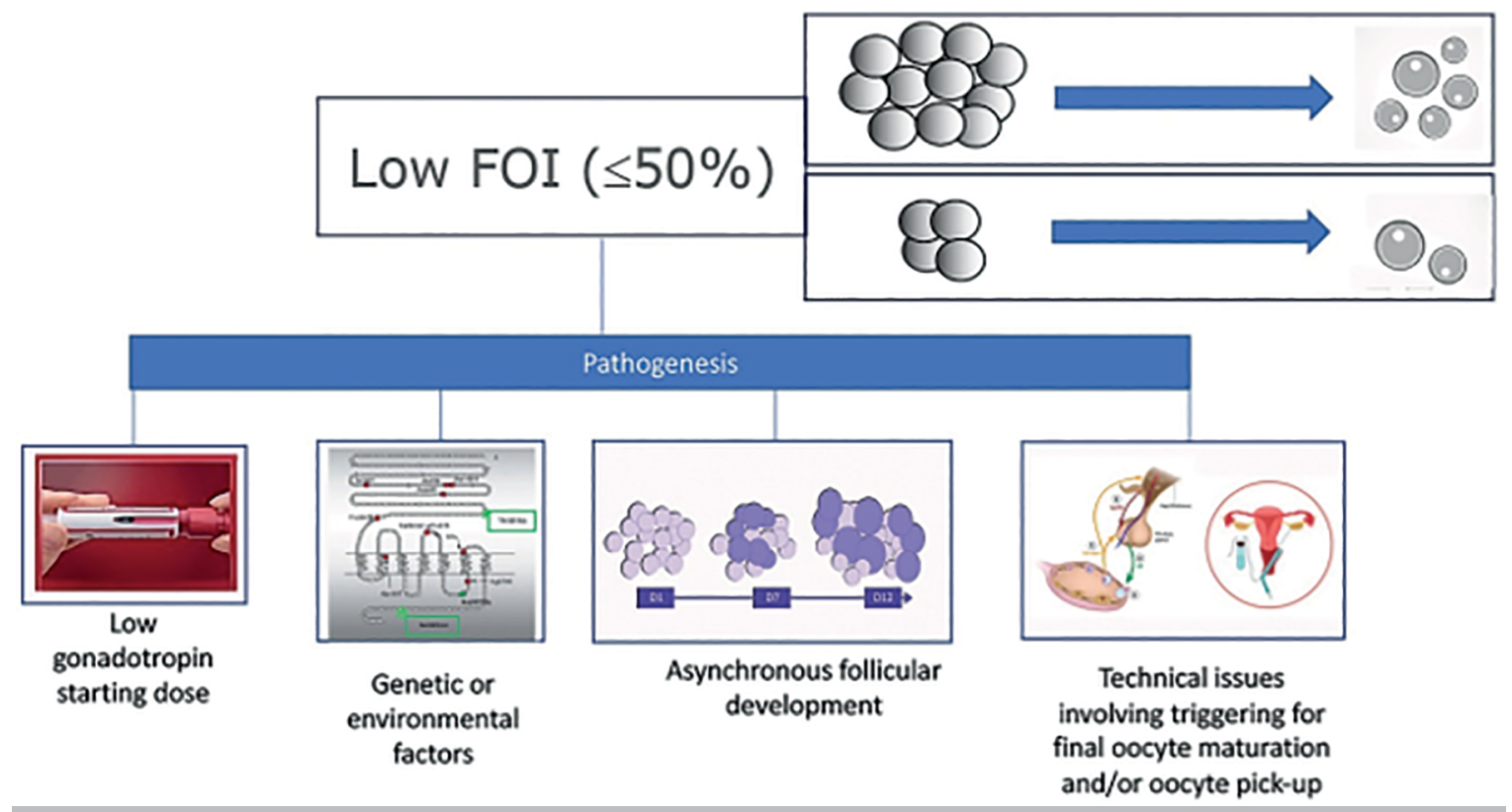

Figure 3. Pathogenesis of low follicle-to-oocyte index (FOI). Reprint from Alviggi et al. Understanding Ovarian Hypo-Response to Exogenous Gonadotropin in Ovarian Stimulation and Its New Proposed MarkerThe Follicle-To-Oocyte (FOI) Index. Front Endocrinol. 2018; 9:589. This is an open-access article distributed under the terms of the Creative Commons Attribution License (CC BY).

according to the POSEIDON criteria. The authors concluded that individualizing the dose of gonadotrophins to be used during OS based on AFC did not increase CLBR when compared to non-individualization, using a 150 IU fixed daily dose of gonadotropins (Van Tilborg et al., 2017a; 2017b; Oudshoorn et al., 2017). Moreover, it was emphasized that the differences in prognosis among the four POSEIDON groups were based mainly on age and that the number of retrieved oocytes had little impact on CLBR. However, several researchers for a multitude of reasons, minimizing the clinical relevance of the findings (Haahr et al., 2018a; 2018b; La Marca et al., 2018; Sunkara \& Polyzos, 2018), heavily criticized the OPTIMIST study. In contrast to the original OPTIMIST study, the study by Leijdekkers et al. (2019) reports staggering numbers underlining that non-individualization is detrimental to patients, when considering CLBR per treatment cycle. In the study by Leijdekkers et al. (2019), among the 985 women randomized to receive 150 IU FSH daily, 782 would be expected to have an adequate ovarian response, based on AMH levels. However, alarming levels of hypo-response to ovarian stimulation were identified, since 360 women of the $782(46 \%)$ had a sub-optimal number of oocytes retrieved, i.e., <= 9 oocytes, and could be classified as POSEIDON 1 or 2 . A normal response to treatment (10-15 oocytes) was seen in $30.1 \%$, only, (242/782) and a hyperresponse ( $>15$ oocytes) in $23 \%(180 / 782)$ of all patients.

Thus, from these data revealing a high incidence of hypo-responses after OS, it is clear that patients would have benefitted from an individualized gonadotropin dosing. Moreover, Leijdekkers et al. (2019) concluded that the CLBR of the low-prognosis patient was approximately $56 \%$ over 18 months, and varied between POSEIDON subgroups, which was primarily attributed to the impact of age. However, after carefully evaluating data and the supplemental material, it becomes obvious that not only female age, but also the ovarian response to treatment have an impact on cumulative reproductive outcomes (Esteves et al., 2019c). This conclusion can be reached by comparing the different CLBRs per cycle in patients having a normal response to those classified as POSEIDON groups 1 to 4 . Patients who had a normal response to OS achieved a higher CLBR per cycle when compared to patients with low prognosis according to the POSEIDON stratification. Thus, while the normal responder group of that study had a CLBR of $52 \%$ per cycle, POSEIDON groups $1,2,3$ and 4 patients had CLBRs of $39 \%, 20 \%, 29 \%$, and $17 \%$, respectively. These differences in reproductive outcomes are clinically highly relevant, even though in the study mentioned above they were not statistically different, most probably due to the small sample size, which might have resulted in an imprecise estimate of the treatment effect (Stocking et al., 2019).

Furthermore, although the OPTIMIST study concluded that individualization of stimulation, based on the ovarian reserve of the patient did not add benefits vis-a-vis the CLBR after 18 months of treatment, Leijdekkers et al. (2019), using the database from the OPTIMIST study, showed that the lack of OS individualization in IVF patients was detrimental. Indeed, the authors showed a lower-thanexpected response during ovarian stimulation in patients who received a non-individualized and fixed gonadotropin dose, which resulted in the retrieval of fewer oocytes than expected, reducing the CLBR per cycle. Finally, the study highlights the importance of correctly defining the primary endpoint when evaluating the CLBR (Leijdekkers et al., 2019). 


\section{MANAGEMENT OF POSEIDON POOR PROGNOSIS PATIENTS $<$ AFC $<5$ AND/OR AMH $<1.2 \mathrm{NG} / \mathrm{ML}$ GROUP 3, YOUNG (AGE<35) "Poor reserve - good quality"

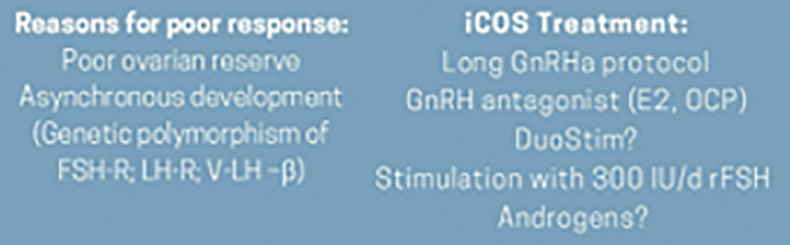

Embryo Transfer strategy: Fresh transfer

Oocyto/embryo accumulation and FET Moasuro of succoss:

In average, a total of $4 \cdot 5$ oocytes are needed to obtain one euploid embryo
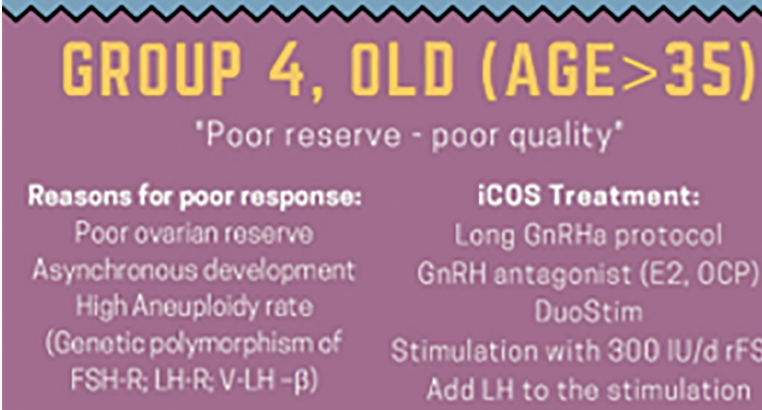

- poor quality'

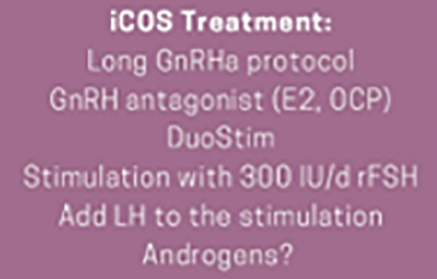

Embryo Transfer strategy: Fresh transfor

Oocyto/ombryo accumulation, PGS? and FET (Occyte donation)

Messure of success:

In average, at least 12 oocytes are needed to obtain one euploid embryo

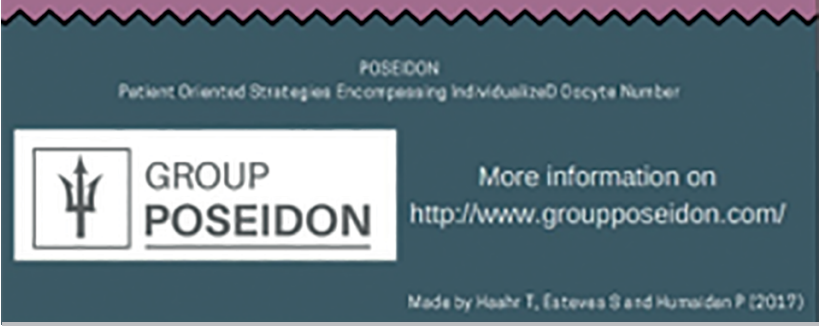

Figure 4. Overview of low prognosis patients according to POSEIDON groups 3 and 4 , including pathogenesis and treatment options. Reprint from: Haahr et al. Individualized controlled ovarian stimulation in expected poor-responders: an update. Reprod Biol Endocrinol. $2018 ; 16: 20$. This is an open-access article distributed under the terms of the Creative Commons Attribution License (CC BY).
From the patient's perspective, it is not fair to compare CLBR over multiple cycles and conclude that the outcome is not inferior to another strategy, if the patient needs to undergo more treatment cycles to achieve the same outcome compared to a personalized strategy. The focus of the patient is to have a baby, undergoing the lowest possible number of cycles and interventions, and in the shortest period. Thus, according to the POSEIDON stratification, low prognosis should be interpreted taking into consideration the CLBR per initiated cycle (Esteves et al., 2019c). The above-discussed differences in reproductive outcomes and prognosis among different POSEIDON groups were explored further in two recent studies using large databases (Li et al., 2019; Shi et al., 2019).

Li et al. (2019) retrospectively evaluated 26,697 IVF cycles in POSEIDON group patients and calculated the optimal and conservative CLBR per cycle. The optimal estimate was based on the reported data and assumed that the CLBR in women who discontinued ART treatment without a live birth would be the same as that of women who continued treatment. In contrast, the conservative estimate assumes that those who discontinue ART treatment have a live-birth rate of zero. In POSEIDON groups 1, 2, 3, and 4, the CLBRs per initiated cycle were $56.0 \%, 30.1 \%, 14.7 \%$, and $6.6 \%$ respectively. After three completed cycles, the optimal and conservative CLBR were $83.9 \%$ and $66.1 \%, 53.7 \%$ and $37.7 \%$, and $44.2 \%, 28.0 \%$, $14.2 \%$ and $9.7 \%$, in groups $1,2,3$, and 4 , respectively ( $\mathrm{Li}$ et al., 2019). In another large analysis, Shi et al. (2019) retrospectively evaluated 18,455 IVF cycles comparing the outcomes of the four POSEIDON groups, including non-low prognosis patients classified as patients with an AFC $>=5$ and a previous number of oocytes retrieved $>9$ oocytes (Group 5), as well as non-low prognosis patients classified as patients with an AFC $>=5$ and no previous OS (Group 6). The non-low prognosis patients (Groups 5 and 6) achieved a CLBR of $53.5 \%$ and $66.9 \%$, respectively, and, thus, the highest CLBR among all groups analyzed. In contrast, POSEIDON groups 1, 2, 3, and 4 had a CLBR of $44.6 \%, 24.5 \%, 35.5 \%$, and $12.7 \%$, respectively (Shi et al., 2019).

The aforementioned results of large data analyses reveal the importance of the novel stratification proposed by the POSEIDON group, clearly showing that first of all the four groups defined by POSEIDON include patients with a poorer reproductive prognosis when compared to the normal reserve, normal responder patient; secondly, that CLBRs are different among the 4 POSEIDON groups, and thirdly, that the age of the patient is a crucial factor for the outcome of an IVF cycle; however, the ovarian response to stimulation in terms of the number of oocytes retrieved is equally important when considering the CLBR per cycle.

\section{POSEIDON's metric of success}

The ability to retrieve the number of oocytes needed to obtain at least one euploid blastocyst for transfer in each patient was introduced by the POSEIDON group as a surrogate metric of success in ART (Alviggi et al., 2016; Humaidan et al., 2016). This metric was not intended to replace live birth rate (LBR), which remains the primary endpoint for couples undergoing ART. Moreover, the POSEIDON endpoint does not imply that pre-implantation genetic testing for aneuploidy (PGT-A) should be routinely performed during ART. On the contrary, it adds to the current knowledge as it provides a logical endpoint for clinicians providing care to women undergoing ART. Since the transfer of an euploid embryo provides - at any given age - implantation rates in the range of $50-60 \%$ (Forman et al., 2013), clinicians could plan a patient-oriented 


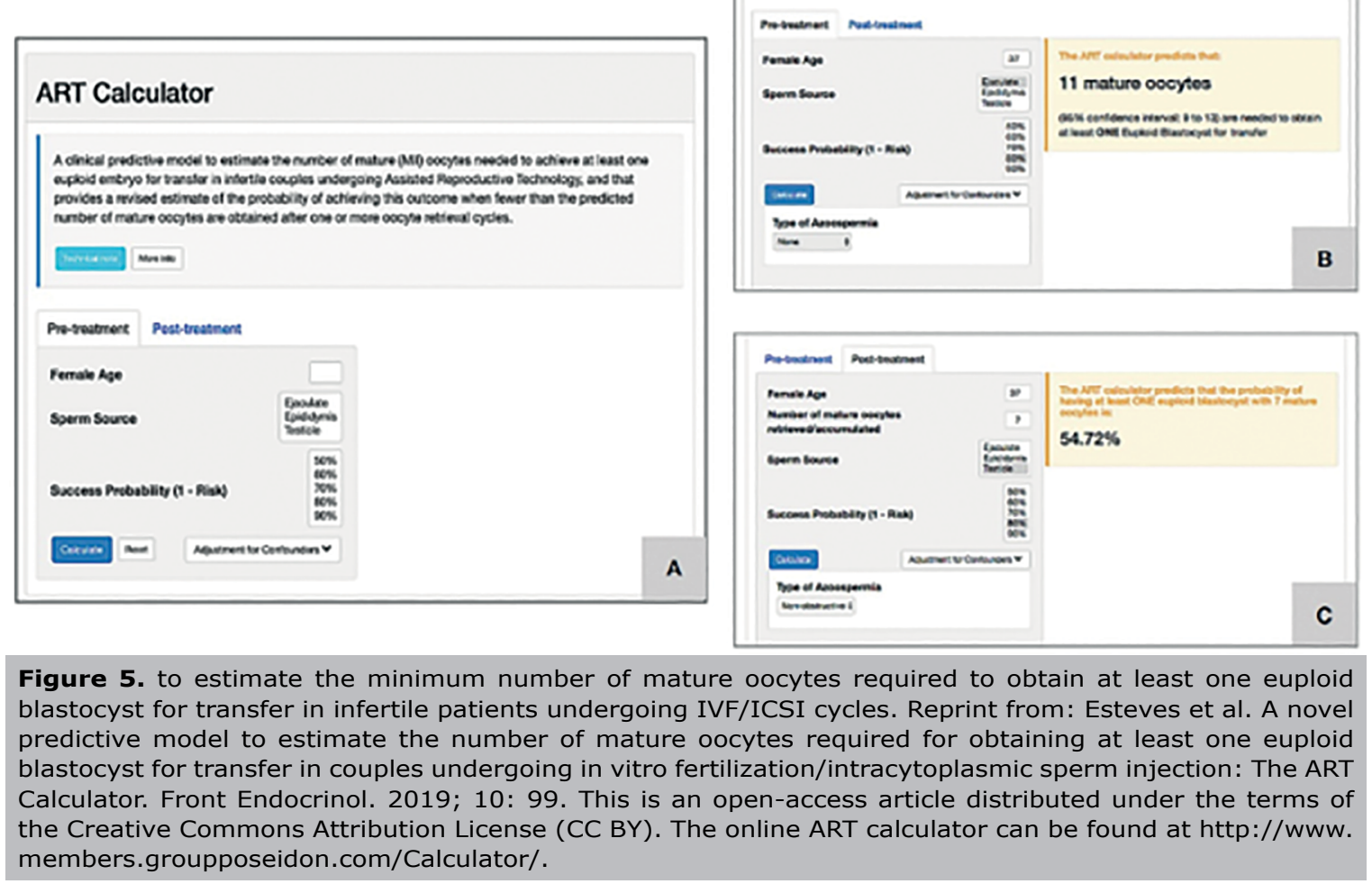

treatment with the mindset to achieve the POSEIDON metric.

The ART calculator: a predictive tool to estimate the POSEIDON metric

The ART Calculator was developed to estimate the minimum number of metaphase II (MII) oocytes required to have at least one euploid blastocyst for transfer in patients undergoing ART (Esteves et al., 2019b) - Figure $5 A$.

This predictive tool was developed based on clinical and embryonic data of infertile couples subjected to IVF/ICSI and PGT-A. Twenty-six co-variates were analyzed, including patient demographics and treatment characteristics using the LASSO logistic regression method for variable selection. Among these co-variates, female age, type of sperm used for ICSI, and MII oocytes $(p<0.0001)$ were deemed relevant for model building. The model equation provides the individualized probability of blastocyst euploidy per MII oocyte, given the female age and sperm source (and type of azoospermia), with $72 \%$ accuracy. Using mathematic equations, an online calculator was developed, in which the user can set the probability of success, i.e. the probability of having at least one euploid blastocyst when the estimated number of MII oocytes is achieved. Thus, two types of predictions can be made. Pre-treatment, the ART calculator estimates the minimum number of mature oocytes, with its associated $95 \%$ confidence interval, to achieve $\geq 1$ euploid blastocyst for transfer in infertile couples undergoing IVF/ ICSI. Clinicians should input the patient age and the sperm source to be used for IVF/ICSI. If the option 'Testicle' is marked, then the type of azoospermia should be also defined. The probability of success is set by the user and indicates the chance of having $\geq 1$ euploid blastocyst when the predicted number of mature oocytes is achieved. Its complement is the risk, i.e., the chance of having no (zero) euploid blastocysts when the predicted number of oocytes is achieved. Once the button 'calculate' is pressed, a text box will pop-up on the right side of the screen, indicating the predicted minimum number of mature oocytes needed for obtaining at least one euploid blastocyst, with its $95 \%$ confidence interval (Figure 5B). Post-treatment, it provides a revised estimate of the probability of achieving $\geq 1$ euploid blastocyst when fewer than the predicted number of mature oocytes are obtained after $\geq 1$ oocyte retrieval cycle, i.e., when fewer than the predicted number of mature oocytes are obtained after one or more oocyte retrieval cycles, clinicians should input the pretreatment information and the actual number of mature oocytes collected or accumulated. As in the pretreatment model, the user sets the probability of success. Once the button 'calculate' is pressed, a text box will pop-up on the right side of the screen, indicating the predicted probability of achieving $\geq 1$ euploid blastocyst with the number of mature oocytes available (Figure 5C). (http://www.members. groupposeidon.com/Calculator/).

A multicenter and international collaborative group was created to perform the external validation of the ART calculator. ART databases concerning infertile couples undergoing IVF/ICSI and PGT-A from three Fertility Centers (Italy, Brazil, and Turkey) were utilized. In the study, 1,464 patients, 9,779 MII oocytes, and 3,108 blastocysts were evaluated. A validation model was developed, using the same roadmap of the ART calculator. Like in the ART calculator, female age and type of sperm are relevant predictors of blastocyst euploidy. High correlations ( $r \sim 0.90)$ were found between the outputs of the ART Calculator 


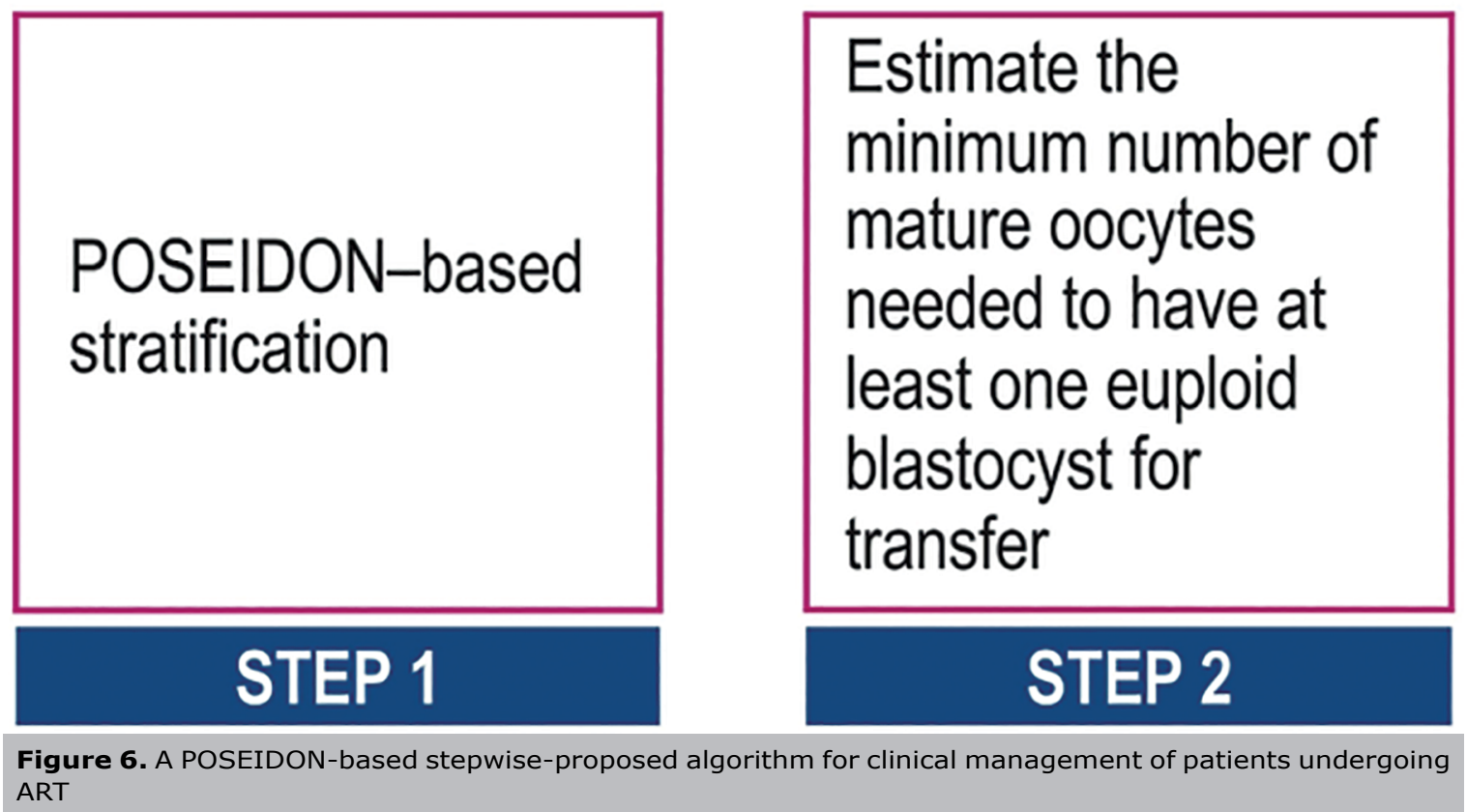

and validation model. Moreover, the frequency of patients in the validation dataset who (i) reached the minimum number of MII oocytes (estimated by ART Calculator), and (ii) who had at least one euploid blastocyst matched the ART Calculator output; thus, suggesting generalizability (Esteves et al., 2019b).

\section{Use of POSEIDON criteria in Clinical Practice}

Figure 6 depicts (http://www.members.groupposeidon. com/Calculator/) a stepwise algorithm for clinical management of patients undergoing ART. The eligible patient is first of all classified according to the POSEIDON criteria. Secondly, the minimum number of MII oocytes required to obtain at least one euploid blastocyst is estimated with the aid of the ART calculator. Lastly, patientoriented treatment strategies to achieve the individualized oocyte number are implemented. It is out of the scope of the present review to discuss possible strategies for each POSEIDON group, however, comprehensive reviews on the subject can be found elsewhere (see also Figures 2 and 7).

\section{CONCLUSIONS}

The POSEIDON stratification of the low prognosis patient was primarily introduced to provide a more detailed stratification of the low prognosis patient undergoing ART, with the ultimate goal of offering clinicians the guidance concerning the most suitable patient-oriented strategies to achieve the suggested oocyte number needed for one euploid blastocyst (Poseidon's metric of success). The novel criteria, therefore, categorize patients according to their prognosis, emphasizing how female age and its related embryo aneuploidy rate, as well as oocyte number are important factors in the success of ART. Added to this, the POSEIDON criteria included the "unexpected poor/suboptimal responders" as a distinct category of "low prognosis" patients. The POSEIDON stratification is suggested to be a counseling instrument to help clinicians set the expectations of any given patient prior to OS. Moreover, the POSEIDON criteria introduced an objective measure of success for an OS cycle, namely the number of oocytes needed to obtain one euploid blastocyst for transfer. The ART calculator can be used to estimate such numbers, thus, allowing open and transparent reporting of information about the number of oocytes needed to obtain an euploid blastocyst, possibly facilitating a mature discussion about therapeutic alternatives and costs. Lastly, the POSEIDON criteria might allow selection of more homogeneous groups of patients in interventional trials, including the use of metrics, in particular, the follicle-tooocyte index (FOI) and the number of mature oocytes needed to achieve at least one euploid blastocyst, as secondary endpoints.

\section{ACKNOWLEDGEMENTS}

Chloé Xilinas, for her help drawing Figure 1.

\section{Funding}

None

\section{CONFLICTS OF INTEREST}

MR received honoraria from Merck lectures. TH received honoraria for Merck lectures IBSA, Besins and Ferring. PH received unrestricted research grants from MSD, Merck, and Ferring as well as honoraria for MSD lectures, Merck, Gedeon-Richter, Theramex, and IBSA. SCE received honoraria for Merck, Gedeon-Richter, and Besins lectures, and research grants from Merck. PH and SCE are cofounders of the POSEIDON criteria.

\section{Corresponding Author:}

Matheus Roque

MATER PRIME - Reproductive Medicine

São Paulo, SP, Brazil

Email: matheusroque@hotmail.com 


\section{Best practice in Poseidon groups 3 and 4}

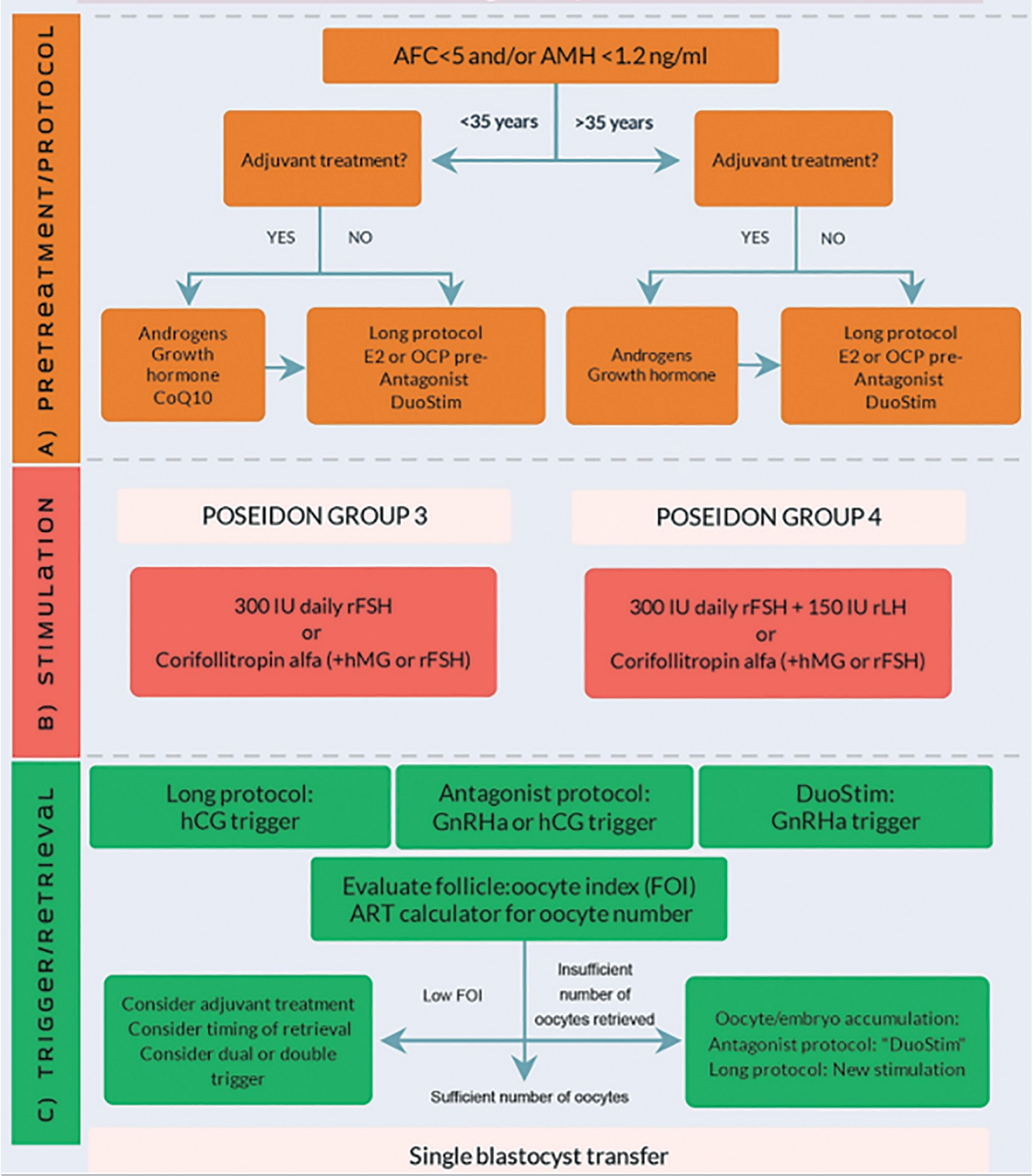

Figure 7. Management of POSEIDON groups 3 and 4. Reprint from: Haahr et al. Management Strategies for POSEIDON Groups 3 and 4. Front Endocrinol. 2019;10:614. This is an open-access article distributed under the terms of the Creative Commons Attribution License (CC BY). 


\section{REFERENCES}

Alviggi C, Andersen CY, Buehler K, Conforti A, Placido G, Esteves SC, Fischer R, Galliano D, Polyzos NP, Sunkara SK, Ubaldi FM, Humaidan P; Poseidon Group (Patient-Oriented Strategies Encompassing Individualized Oocyte Number). A new more detailed stratification of low responders to ovarian stimulation: from a poor ovarian response to a low prognosis concept. Fertil Steril. 2016;105:1452-3. PMID: 26921622 DOI: 10.1016/j.fertnstert.2016.02.005

Alviggi C, Conforti A, Esteves SC, Vallone R, Venturella $\mathrm{R}$, Staiano S, Castaldo $\mathrm{E}$, Andersen $\mathrm{CY}$, Placido G. Understanding ovarian hypo-response to exogenous gonadotropin in ovarian stimulation and its new proposed marker-the follicle-to-oocyte (FOI) index. Front Endocrinol. 2018;9:589. PMID: 30386293 DOI: 10.3389/ fendo.2018.00589

Boots CE, Bernardi LA. Bologna criteria: clinically or academically relevant? Fertil Steril. 2018;109:59-60. PMID: 29307403 DOI: 10.1016/j.fertnstert.2017.10.022

Bozdag G, Polat M, Yarali I, Yarali H. Live birth rates in various subgroups of poor ovarian responders fulfilling the Bologna criteria. Reprod Biomed Online. 2017;34:639-44. PMID: 28366519 DOI: 10.1016/j.rbmo.2017.03.009

Cohen J, Chabbert-Buffet N, Darai E. Diminished ovarian reserve, premature ovarian failure, poor ovarian responder--a plea for universal definitions. J Assist Reprod Genet. 2015;32:1709-12. PMID: 26463876 DOI: 10.1007/ s10815-015-0595-y

Conforti A, Esteves SC, Picarelli S, Iorio G, Rania E, Zullo F, Placido G, Alviggi C. Novel approaches for diagnosis and management of low prognosis patients in assisted reproductive technology: the POSEIDON concept. Panminerva Med. 2019a;61:24-9. PMID: 30021418 DOI: 10.23736/S0031-0808.18.03511-5

Conforti A, Esteves SC, Cimadomo D, Vaiarelli A, Di Rella F, Ubaldi FM, Zullo F, Placido G, Alviggi C. Manejo de mulheres com uma resposta ovariana inesperada baixa à gonadotrofina. Front Endocrinol. 2019b; 10: 387. DOI: 10.3389/fendo.2019.00387

Drakopoulos P, Blockeel C, Stoop D, Camus M, De Vos M, Tournaye $H$, Polyzos NP. Estimulação ovariana convencional e transferência de embrião único para FIV / ICSI. Quantos oócitos precisamos para maximizar as taxas cumulativas de nascidos vivos após a utilização de todos os embriões frescos e congelados? Hum Reprod. 2016; 31: 370-6. PMID: 26724797

Dyer S, Chambers GM, Mouzon J, Nygren KG, ZegersHochschild F, Mansour R, Ishihara O, Banker M, Adamson GD. Relatório mundial do comitê internacional para monitoramento de tecnologias de reprodução assistida: tecnologia de reprodução assistida 2008, 2009 e 2010. Hum Reprod. 2016; 31: 1588-609. PMID: 27207175 DOI: 10.1093/humrep/dew082

Esteves SC, Roque M, Bedoschi GM, Conforti A, Humaidan $P$, Alviggi C. Definindo pacientes de baixo prognóstico submetidos à tecnologia de reprodução assistida: critérios POSEIDON - o porquê. Front Endocrinol. 2018; 9: 461. PMID: 30174650 DOI: $10.3389 /$ fendo.2018.00461
Esteves SC, Alviggi C, Humaidan P, Fischer R, Andersen CY, Conforti A, Bühler K, Sunkara SK, Polyzos NP, Galliano D, Grynberg M, Yarali H, Özbek IY, Roque M, Vuong LN, Banqueiro M, Rienzi L , Vaiarelli A, Cimadomo D, Ubaldi FM. Os critérios POSEIDON e sua medida de sucesso sob o ponto de vista de clínicos e embriologistas. Front Endocrinol. 2019a; 10: 814. DOI: 10.3389/fendo.2019.00814

Esteves SC, Carvalho JF, Bento FC, Santos J. Um novo modelo preditivo para estimar o número de oócitos maduros necessários para a obtenção de pelo menos um blastocisto euplóide para transferência em casais submetidos à fertilização in vitro / injeção intracitoplasmática de espermatozóide: a calculadora ART. Front Endocrinol. 2019b; 10: 99. DOI: 10.3389/fendo.2019.00099

Esteves SC, Roque M, Sunkara SK, Conforti A, Ubaldi FM, Humaidan $\mathrm{P}$, Alviggi C. A quantidade de oócitos, assim como a qualidade do oócito, desempenha um papel significativo para a taxa cumulativa de nascidos vivos de um paciente com critérios POSEIDON. Hum Reprod. 2019c; 34: 25557. DOI: $10.1093 /$ humrep/dez181

Ferraretti AP, La Marca A, Fauser BC, Tarlatzis B, Nargund G, Gianaroli L; Grupo de Trabalho ESHRE sobre Definição de Resposta Fraca ovariana. Consenso ESHRE sobre a definição de 'resposta fraca' à estimulação ovariana para fertilização in vitro: os critérios de Bolonha. Hum Reprod. 2011; 26: 1616-24. PMID: 21505041 DOI: 10.1093/ humrep/der092

Forman EJ, Hong KH, Ferry KM, Tao X, Taylor D, Levy $B$, Treff NR, Scott Junior RT. Fertilização in vitro com transferência única de blastocisto euploide: um ensaio clínico randomizado. Fertil Steril. 2013; 100: 100-7.e1. DOI: $10.1016 /$ j.fertnstert.2013.02.056

Gallot V, Silva AL, Genro V, Grynberg M, Frydman N, Fanchin R. A responsividade do folículo antral à administração do hormônio folículo-estimulante avaliada pelo Folicular Output RaTe (FORT) pode prever o resultado de transferência de embrião-fertilização in vitro. Hum Reprod. 2012; 27: 1066-72. DOI: 10.1093/humrep/der479

Genro VK, Grynberg M, Scheffer JB, Roux I, Frydman R, Fanchin R. Os níveis séricos de hormônio anti-mulleriano estão negativamente relacionados à RaTe de Saída Folicular (FORT) em mulheres normociclando submetidas a hiperestimulação ovariana controlada. Hum Reprod. 2011; 26: 671-7. PMID: 21177311 DOI: 10.1093/humrep/ deq361

Goldman KN, Noyes NL, Knopman JM, McCaffrey C, Grifo JA. Oocyte efficiency: does live birth rate differ when analyzing cryopreserved and fresh oocytes on a per-oocyte basis? Fertil Steril. 2013;100:712-7. PMID: 23721713 DOI: $10.1016 /$ j.fertnstert.2013.04.040

Goldman RH, Racowsky C, Farland LV, Munné S, Ribustello $\mathrm{L}$, Fox JH. Predicting the likelihood of live birth for elective oocyte cryopreservation: a counseling tool for physicians and patients. Hum Reprod. 2017;32:853-9. PMID: 28166330 DOI: $10.1093 /$ humrep/dex008

Haahr T, Esteves SC, Humaidan P. Individualized controlled ovarian stimulation in expected poor-responders: an update. Reprod Biol Endocrinol. 2018a;16:20. PMID: 29523204 DOI: $10.1186 /$ s12958-018-0342-1 
Haahr T, Esteves SC, Humaidan P. Poor definition of poor-ovarian response results in misleading clinical recommendations. Hum Reprod. 2018b;33:979-80. PMID: 29596585 DOI: 10.1093/humrep/dey059

Haahr T, Dosouto C, Alviggi C, Esteves SC, Humaidan P. Management strategies for POSEIDON groups 3 and 4 . Front Endocrinol. 2019;10:614. PMID: 31572298 DOI: 10.3389/fendo.2019.00614

Hu L, Bu Z, Guo Y, Su Y, Zhai J, Sun Y. Comparison of different ovarian hyperstimulation protocols efficacy in poor ovarian responders according to the Bologna criteria. Int J Clin Exp Med. 2014;7:1128-34. PMID: 24955194

Humaidan P, Alviggi C, Fischer R, Esteves SC. The novel POSEIDON stratification of 'low prognosis patients in assisted reproductive technology' and its proposed marker of successful outcome. F1000Res. 2016;5:2911. PMID: 28232864 DOI: $10.12688 /$ f1000research.10382.1

Humaidan P, Chin W, Rogoff D, D'Hooghe T, Longobardi S, Hubbard J, Schertz J; ESPART Study Investigators. Efficacy and safety of follitropin alfa/lutropin alfa in ART: a randomized controlled trial in poor ovarian responders. Hum Reprod. 2017;32:544-55. PMID: 28137754 DOI: 10.1093/humrep/dew360

La Marca A, Grisendi V, Giulini S, Sighinolfi G, Tirelli A, Argento $C, \operatorname{Re} C$, Tagliasacchi D, Marsella T, Sunkara SK. Live birth rates in the different combinations of the Bologna criteria poor ovarian responders: a validation study. J Assist Reprod Genet. 2015;32:931-7. PMID: 25925345 DOI: $10.1007 / \mathrm{s} 10815-015-0476-4$

La Marca A, Blockeel C, Bosch E, Fanchin R, Fatemi HM, Fauser BC, García-Velasco JA, Humaidan P, Tarlatzis BC, Nelson SM. Individualized FSH dosing improves safety and reduces iatrogenic poor response while maintaining livebirth rates. Hum Reprod. 2018;33:982-3. PMID: 29596626 DOI: $10.1093 /$ humrep/dey061

Leijdekkers JA, Eijkemans MJ, Van Tilborg TC, Oudshoorn SC, Van Golde RJ, Hoek A, Lambalk CB, Bruin JP, Fleischer K, Mochtar MH, Kuchenbecker WK, Laven JSE, Mol BW, Torrance HL, Broekmans FJ; OPTIMIST Study Group. Cumulative live birth rates in low-prognosis women. Hum Reprod. 2019;34:1030-41. DOI: 10.1093/ humrep/dez051

Li Y, Li X, Yang X, Cai S, Lu G, Lin G, Humaidan P, Gong F. Cumulative live birth rates in low prognosis patients according to the POSEIDON criteria: an analysis of 26,697 cycles of in vitro fertilization/intracytoplasmic sperm injection. Front Endocrinol (Lausanne). 2019;10:642. PMID: 31608011 DOI: 10.3389/fendo.2019.00642

Olgan S, antagonista de Humaidan P. GnRH e cotratamento de letrozol em pacientes com reserva ovariana diminuída: um estudo de prova de conceito. Reprod Biol. 2017; 17: 105-10. PMID: 28173995 DOI: 10.1016/j. repbio.2017.01.006
Oudshoorn SC, Van Tilborg TC, Eijkemans MJ, Oosterhuis GJ, Friederich J, Van Hooff MH, Van Santbrink EJ, Brinkhuis EA, Smeenk JM, Kwee J, Koning $\mathrm{CH}$, Groen $\mathrm{H}$, Lambalk CB, Mol BW, Broekmans FJ, Torrance HL; Grupo de estudo OPTIMIST. Dosagem de FSH individualizada versus padrão em mulheres começando FIV / ICSI: um RCT. Parte 2: o hiper-respondedor previsto. Hum Reprod. 2017; 32: 250614. DOI: $10.1093 /$ humrep/dex319

Pandian Z, McTavish AR, Aucott L, Hamilton MP, Bhattacharya $\mathrm{S}$. Interventions for 'pobres respondedores' à hiperestimulação ovariana controlada $(\mathrm{COH})$ na fertilização in vitro (FIV). Cochrane Database Syst Rev. 2010;: CD004379. PMID: 20091563 DOI: 10.1002/14651858.CD004379.pub3

Papathanasiou A, Searle BJ, King NM, Bhattacharya S. Tendências na pesquisa de 'resposta fraca': lições aprendidas com RCTs na concepção assistida. Atualização Hum Reprod. 2016; 22: 306-19. PMID: 26843539 DOI: 10.1093/humupd/dmw001

Polyzos NP, Devroey P. Uma revisão sistemática de ensaios clínicos randomizados para o tratamento de respostas ovarianas fracas: há alguma luz no fim do túnel? Fertil Steril. 2011; 96: 1058-61.e7. PMID: 22036048 DOI: 10.1016/j.fertnstert.2011.09.048

Polyzos NP, Blockeel C, Verpoest W, De Vos M, Stoop D, Vloeberghs V, Camus M, Devroey P, Tournaye H. Taxas de nascimentos vivos após FIV de ciclo natural em mulheres com resposta ovariana pobre de acordo com os critérios de Bolonha. Hum Reprod. 2012; 27: 3481-6. PMID: 22940767 DOI: $10.1093 /$ humrep/des318

Polyzos NP, Devos M, Humaidan P, Stoop D, Ortega-Hrepich $\mathrm{C}$, Devroey $\mathrm{P}$, Tournaye $\mathrm{H}$. Corifollitropin alfa seguido por rFSH em um protocolo de antagonista de GnRH para pacientes com baixa resposta ovariana: um estudo piloto observacional. Fertil Steril. 2013; 99: 422-6. PMID: 23084565 DOI: $10.1016 /$ j.fertnstert.2012.09.043

Polyzos NP, Drakopoulos P, Parra J, Pellicer A, SantosRibeiro S, Tournaye H, Bosch E, Garcia-Velasco J. Taxas cumulativas de nascidos vivos de acordo com o número de oócitos recuperados após a primeira estimulação ovariana para fertilização in vitro / intracitoplasmática injeção de esperma: uma análise multinacional multicêntrica incluindo 15.000 mulheres. Fertil Steril. 2018; 110: 661-70.e1. PMID: 30196963 DOI: 10.1016/j.fertnstert.2018.04.039

Shi W, Zhou H, Tian L, Zhao Z, Zhang W, Shi J. Taxas cumulativas de nascidos vivos de pacientes com bom e baixo prognóstico de acordo com os critérios POSEIDON: uma análise de centro único de 18.455 ciclos de tratamento. Front Endocrinol. 2019; 10: 409. PMID: 31293519 DOI: 10.3389/fendo.2019.00409

Siristatidis C, Sergentanis TN, Kanavidis P, Trivella M, Sotiraki M, Mavromatis I, Psaltopoulou T, Skalkidou A, Petridou ET. Hiperestimulação ovariana controlada para fertilização in vitro: impacto no câncer ovariano, endometrial e cervical - uma revisão sistemática e metaanálise. Atualização Hum Reprod. 2013; 19: 105-23. PMID: 23255514 DOI: 10.1093/humupd/dms051 
Stocking K, Wilkinson J, Lensen S, Brison DR, Roberts SA, Vail A. As intervenções em medicina reprodutiva são avaliadas quanto aos efeitos plausíveis e clinicamente relevantes? Uma revisão sistemática de poder e precisão em ensaios e meta-análises. Hum Reprod. 2019; 34: 65965. PMID: 30838395 DOI: 10.1093/humrep/dez017

Sunkara SK, Polyzos NP. OPTIMIST trial: optimistic evidence? Hum Reprod. 2018;33:983-4. PMID: 29596578 DOI: $10.1093 /$ humrep/dey062

Sunkara SK, Rittenberg V, Raine-Fenning N, Bhattacharya S, Zamora J, Coomarasamy A. Association between the number of eggs and live birth in IVF treatment: an analysis of 400135 treatment cycles. Hum Reprod. 2011;26:176874. PMID: 21558332 DOI: 10.1093/humrep/der106

Tarlatzis BC, Zepiridis L, Grimbizis G, Bontis J. Clinical management of low ovarian response to stimulation for IVF: a systematic review. Hum Reprod Update. 2003;9:6176. PMID: 12638782 DOI: 10.1093/humupd/dmg007

Ulug U, Ben-Shlomo I, Turan E, Erden HF, Akman MA, Bahceci M. Conception rates following assisted reproduction in poor responder patients: a retrospective study in 300 consecutive cycles. Reprod Biomed Online. 2003;6:439-43. PMID: 12831590 DOI: $10.1016 / S 1472-$ 6483(10)62164-5
Van Tilborg TC, Oudshoorn SC, Eijkemans MJ, Mochtar $\mathrm{MH}$, Van Golde RJ, Hoek A, Kuchenbecker WK, Fleischer K, Bruin JP, Groen H, Van Wely M, Lambalk CB, Laven JS, Mol BW, Broekmans FJ, Torrance HL; OPTIMIST Study Group. Individualized $\mathrm{FSH}$ dosing based on ovarian reserve testing in women starting IVF/ICSI: a multicentre trial and costeffectiveness analysis. Hum Reprod. 2017;32:2485-95. PMID: 29121350 DOI: $10.1093 /$ humrep/dex321

Van Tilborg TC, Torrance HL, Oudshoorn SC, Eijkemans MJC, Koks CAM, Verhoeve HR, Nap AW, Scheffer GJ, Manger AP, Schoot BC, Sluijmer AV, Verhoeff A, Groen H, Laven JS, Mol BW, Broekmans FJ; OPTIMIST Study Group. Individualized versus standard FSH dosing in women starting IVF/ICSI: an RCT. Part 1: the predicted poor responder. Hum Reprod. 2017;32:2496-505. PMID: 29121326 DOI: 10.1093/ humrep/dex318

Zegers-Hochschild F, Adamson GD, Dyer S, Racowsky C, Mouzon J, Sokol R, Rienzi L, Sunde A, Schmidt L, Cooke ID, Simpson JL, Van Der Poel S. The international glossary on infertility and fertility care, 2017. Fertil Steril. 2017;108:393-406. PMID: 28760517 DOI: 10.1016/j. fertnstert.2017.06.005 